\title{
Seismic signature of the COVID-19 lockdown at the city scale: a case study with low-cost seismometers in the city of Querétaro, Mexico
}

\author{
Raphael S. M. De Plaen ${ }^{1}$, Víctor Hugo Márquez-Ramírez ${ }^{1}$, Xyoli Pérez-Campos ${ }^{2}$, F. Ramón Zuñiga ${ }^{1}$, \\ Quetzalcoatl Rodríguez-Pérez ${ }^{1}$, Juan Martín Gómez González ${ }^{1}$, and Lucia Capra ${ }^{1}$ \\ ${ }^{1}$ Centro de Geociencias, Universidad Nacional Autónoma de México, Juriquilla, Querétaro, Mexico \\ ${ }^{2}$ Instituto de Geofísica, Universidad Nacional Autónoma de México, Mexico City, Mexico
}

Correspondence: Raphael S. M. De Plaen (raphael.deplaen@geociencias.unam.mx)

Received: 19 November 2020 - Discussion started: 4 December 2020

Revised: 26 January 2021 - Accepted: 29 January 2021 - Published: 25 March 2021

\begin{abstract}
Seismometers have detected the social response to lockdown measures implemented following the onset of the COVID-19 pandemic in cities around the world. This longlasting pandemic has been a particular challenge in countries such as Mexico, where the informal economy constitutes most of the working population. This context motivated the monitoring of the mobility of populations throughout the various phases of lockdown measures independently of people's access to the internet and mobile technology.

Here we use the variation of anthropogenic seismic noise in the city of Querétaro (central Mexico) recorded by a network of low-cost Raspberry Shake seismic stations to study the spatial and temporal variation of human activity in the city throughout the pandemic and during sporting events. The results emphasize the importance of densifying urban seismic networks and of tracking human activities without the privacy concerns associated with mobile technology.
\end{abstract}

\section{Introduction}

In early 2020, the COVID-19 pandemic took the world by surprise, and, given the absence of a treatment or vaccine, it forced the implementation of lockdown measures to prevent its spread. Like other countries in the world, Mexico progressively implemented confinement measures after the World Health Organization declared it a pandemic on 11 March (WHO, 2020). The first confinement measures, focused on closing schools and university campuses, were declared on
14 March and progressively evolved to a full suspension of non-essential activities on 24 March with the "quédate en casa" ("stay at home") campaign (Secretaría de Salud, 2020a). Lockdown measures came to a slow, progressive relaxation from 1 June after authorities declared the intention to gradually reopen the economy (Secretaría de Salud, 2020b).

The response to lockdown measures in Mexico is of particular interest as it is challenged by the high level of informal economic activity in the country $(\sim 60 \%$; OECD Economic Surveys; Economic and Development Review Committee, 2019). Activities of the informal economy, excluding illicit ones, are not taxed, regulated, or monitored by any form of government and as a result are not subject to social protection or other types of employment benefits (OECD/ILO, 2019). Workers and economic units participating in this economy do not have access to secure work, benefits, welfare protection, or representation, already generating significant risks and vulnerabilities in regular times that are dramatically exacerbated during the COVID-19 pandemic. The uncertainty that arises from this reality is further motivation to monitor and characterize how the lockdown measures were followed in the country to better understand the impact of the pandemic on the different portions of the population and help inform the response of public health agencies and government officials.

Since the beginning of the crisis, community mobility data published by tech and social media companies have significantly contributed to the analysis of social behavior changes following lockdown measures. However, these data result 
from aggregates of the personal history of user time spent at different categories of activities, which is likely to trigger privacy concerns, although it has undergone anonymization procedures (Aktay et al., 2020). Such tools are also confronted with the limitations of access to the internet, especially creating a digital connectivity divide in rural areas, combined with the potentially limited utilization of smartphones. For instance, internet adoption in rural areas of Mexico is estimated at $39.2 \%$ in rural areas with $53.8 \%$ of the population owning smartphones. In contrast, $71.2 \%$ of urban residents have access to the internet and $77.7 \%$ use smartphones (Martínez-Domínguez and Mora-Rivera, 2020).

Recently, anthropogenic seismic noise has also proven to be a good proxy for the reduction of human activities that followed the 2020 lockdown measures worldwide, especially near urban areas (e.g., Cannata et al., 2021; Dias et al., 2020; Lecocq et al., 2020; Poli et al., 2020; Xiao et al., 2020). This phenomenon, although well documented at a global scale, has yet to be analyzed in Mexico, which typically benefits from high seismic station coverage as a result of its significant seismicity. Anthropogenic seismic signals are generated by a wide range of sources from traffic to sporting and cultural events (e.g., Diaz et al., 2020; Green and Bowers, 2008; Riahi and Gerstoft, 2015). When applied to the observation of the impact of confinement and social distancing measures, anthropogenic noise offers a perspective on the scale of the unprecedented measures authorities had to take to mitigate the spread of the pandemic. In most cases in the literature, anthropogenic seismic noise amplitude correlates with community mobility data (e.g., Cannata et al., 2021; Dias et al., 2020; Lecocq et al., 2020). Therefore, analysis of seismic noise may offer the ability to attain mobility information without the privacy-related concerns and limitations of using mobile technology.

Here, we focus on the city of Querétaro, $200 \mathrm{~km}$ northwest of Mexico City. Even though the area has lower seismicity rates than other parts of Mexico, it is currently equipped with a network of seven Raspberry Shake 4D seismic stations spread throughout the city. The relative density of the network combined with the low local seismicity makes this city an ideal laboratory to explore the impact of the lockdown measures on seismic noise and the general signature of human activities observed by seismic instruments.

The lockdown in Mexico was structured in three phases with growing constraints as the number of cases increased in the country from mid-March until June (Table 1). From June on, the authorities implemented a plan towards la nueva normalidad (the "new normality", NN) with a monitoring system regulating the use of public spaces according to the risk of COVID-19 contagion. This system assigns a stoplight color to each state ranging from red to green as a function of the ongoing epidemiological risk (Secretaría de Salud, 2020b, Semáforo COVID-19; Table 2). The different phases of lockdown and stoplight colors are associated with critical additional constraints on non-essential activities. Under the

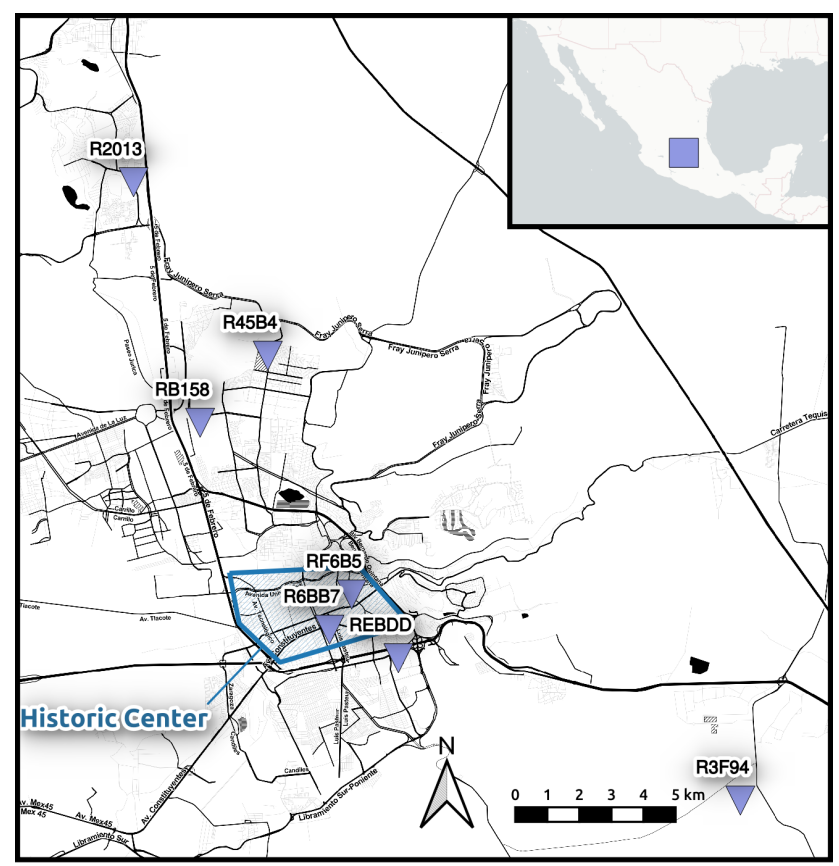

Figure 1. The seismic network of the metropolitan zone of Querétaro. The inverted triangles are the locations of the stations used in this study. The square in the inset shows the location of the city of Querétaro (map tiles by Stamen Design under CC BY 3.0, data by (C) OpenStreetMap contributors, 2020; distributed under a Creative Commons BY-SA License).

assumption that most people respected those regulations, the anthropogenic noise is expected to vary accordingly.

\section{Materials and methods}

\subsection{Data}

The Querétaro metropolitan zone (QMZ) is monitored by a seismic network operated by the Center of Geosciences (UNAM Campus Juriquilla). As of 2020, the network, designed for studies of local and regional events, was composed of seven Raspberry Shake 4D stations that each incorporate a vertical component geophone and a three-component accelerometer (Fig. 1).

These low-cost sensors were demonstrated to perform suitably well for monitoring a large range of local and regional earthquake magnitudes (Anthony et al., 2019). Although the accelerometers are capable of recording larger, more powerful earthquakes, they have high self-noise levels and are not able to resolve most cultural activity. Our analysis in this study is therefore restricted to the vertical component geophone data. All stations record continuous data at a sampling rate of $100 \mathrm{~Hz}$ except for station R2013 recording at $50 \mathrm{~Hz}$. Of the three stations installed near the historic center, RF6B5 and R6BB7 are both installed in cultural centers that 
Table 1. Descriptions of the early phases of the federal lockdown in Mexico (Secretaría de Salud, 2020a).

\begin{tabular}{|c|c|c|}
\hline Phases & $\begin{array}{l}\text { Announcement/ } \\
\text { implementation dates }\end{array}$ & Description \\
\hline Phase 1 & $\begin{array}{l}14 \text { March 2020/ } \\
21 \text { March } 2020\end{array}$ & $\begin{array}{l}\text { Importation of the virus with dozens of identified infected travelers entering the coun- } \\
\text { try; } \\
\text { closing of schools and universities with early recess }\end{array}$ \\
\hline Phase 2 & 24 March 2020 & $\begin{array}{l}\text { Community propagation of the virus, with hundreds of infected people, and the origin } \\
\text { of the infections is no longer well identified; } \\
\text { suspension of classes, events, and meetings of more than } 100 \text { people; suspension of } \\
\text { work activities that involve the mobilization of people in all sectors of society and in- } \\
\text { tensification of basic sanitary prevention measures; } \\
\text { start of the "quédate en casa" campaign }\end{array}$ \\
\hline $\begin{array}{l}\text { State of } \\
\text { sanitary } \\
\text { emergency }\end{array}$ & 30 March 2020 & Immediate suspension of non-essential activities in the public, private, and social sectors \\
\hline Phase 3 & 21 April 2020 & $\begin{array}{l}\text { National epidemiological stage with thousands of confirmed infectious cases throughout } \\
\text { the country; the measures to stay in homes are reinforced with the limitation of non- } \\
\text { essential activities }\end{array}$ \\
\hline
\end{tabular}

Table 2. Categories of the epidemiological risk stoplight during the "new normality" in Mexico (Secretaría de Salud, 2020b).

\begin{tabular}{ll}
\hline Color & Description \\
\hline Red & Only essential businesses are allowed, and people are encouraged to shelter at home. \\
\hline Orange & $\begin{array}{l}\text { Essential businesses are allowed, non-essential businesses are allowed to operate with up to } 30 \% \text { of the personnel, and } \\
\text { open public spaces are opened with a limited capacity. }\end{array}$ \\
\hline Yellow & $\begin{array}{l}\text { All businesses are allowed to operate. Open public spaces are open at regular capacity, and closed public spaces operate } \\
\text { at reduced capacity. All activities must be carried out with basic preventive measures. }\end{array}$ \\
\hline Green & All activities are allowed at regular capacity, including school. \\
\hline
\end{tabular}

had suspended their activities since the beginning of the confinement, and REBDD is installed in the Corregidora soccer arena, which has a capacity of $\sim 34000$.

The stations located further from the center of the city are installed on university campuses (R2013 - UNAM Campus Juriquilla, R45B4 - Universidad Tecnológica de Querétaro, and R3F94 - Universidad Politécnica de Querétaro) and in the Benito Juárez industrial park (RB158). All the network stations are within $5 \mathrm{~km}$ of four-lane highways with $90-100 \mathrm{~km} \mathrm{~h}^{-1}$ speed limits and significant traffic. The period analyzed here extends from 1 November 2019 to 1 October 2020.

\subsection{Anthropogenic noise analysis}

The QMZ network was designed to study natural processes, specifically local and regional tectonic earthquakes, rather than human-generated signals. Nevertheless, the recorded signal is subjected to a significant amount of noise, whether systematic (instrumental noise), natural (microseisms, atmospheric, etc.), or human-made. The latter includes a broad spectrum of potential sources typically recorded between 2 and $20 \mathrm{~Hz}$, such as traffic, public transportation, pedestrians, and industries (e.g., Diaz et al., 2020; Poli et al., 2020).

Human-generated noise is also characterized by strong diurnal variability and higher amplitudes during business days than weekends and public holidays. As a result, we measured the anthropogenic noise by using the signal between 07:00 and 19:00 local time. Using the same method as Lecocq et al. (2020), we computed the power spectral density (PSD) using Welch's method (Welch, 1967) from $30 \mathrm{~min}$ windows with a $50 \%$ overlap.

The time series were extracted from the root mean square (seismic rms) of the time-domain displacement. The seismic rms was first implemented using a narrow band of $1 \mathrm{~Hz}$ for multiple frequencies ranging from 1 to $20 \mathrm{~Hz}$ to better identify the stable frequency range most affected by the lockdown measures (Fig. 2). The resulting time series were then used to identify the Spearman correlation coefficient between each narrowband seismic rms and each community mobility category (Fig. 3). 

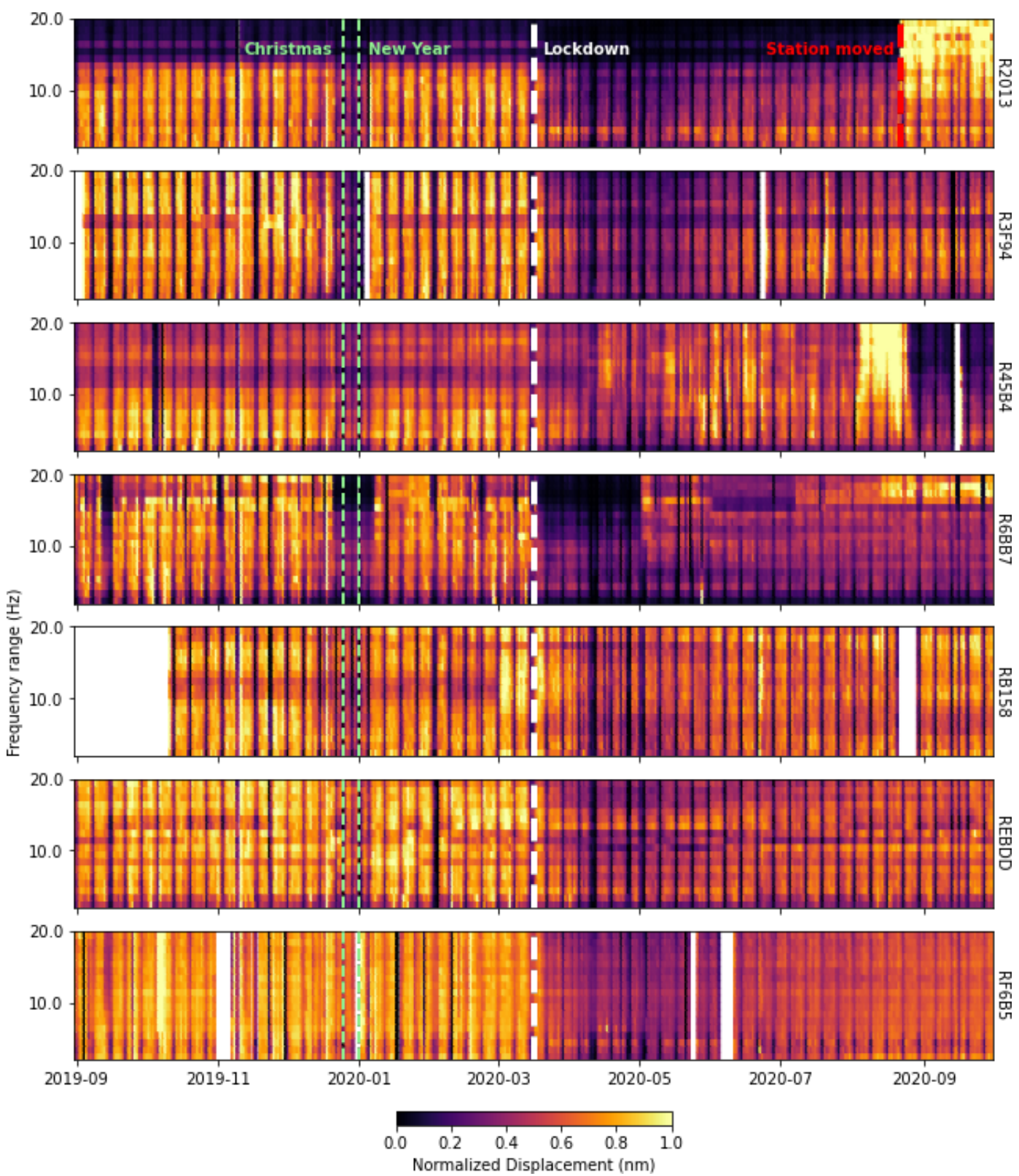

Figure 2. Normalized variation of rms displacement in $1 \mathrm{~Hz}$ frequency bins from 1 to $20 \mathrm{~Hz}$ at all stations. The typical succession of business days and weekends can clearly be observed, but the largest reductions in seismic noise levels are identified during the Christmas holiday (green dashed lines are Christmas and New Year, respectively) and following the implementation of lockdown measures in mid-March 2020 (white dashed line). Note that station R2013 was moved in late August 2020 (red dashed line).

\subsection{Mobility data}

From the beginning of the pandemic, Google, along with other tech and social media companies (e.g., WAZE, Apple, Facebook), started sharing community mobility data created with aggregated, anonymized sets of data from user location histories (Google, 2020). Here we focus on data provided by Google as they are likely to sample a larger portion of the population and more heterogeneous social backgrounds (Borbón González et al., 2018). These reports offer analyses of movement trends over time by geography across different high categories of places defined as retail and recreation, groceries and pharmacies, parks, transit stations, workplaces, and residential. The data reflect the time visitors spent in the different categories of places compared to baseline days, calculated as the median value from the arbitrary 5 -week period from 3 January to 6 February 2020. Each value in the report is therefore a measurement relative to seven individual values of the corresponding day of the week during the baseline period. 


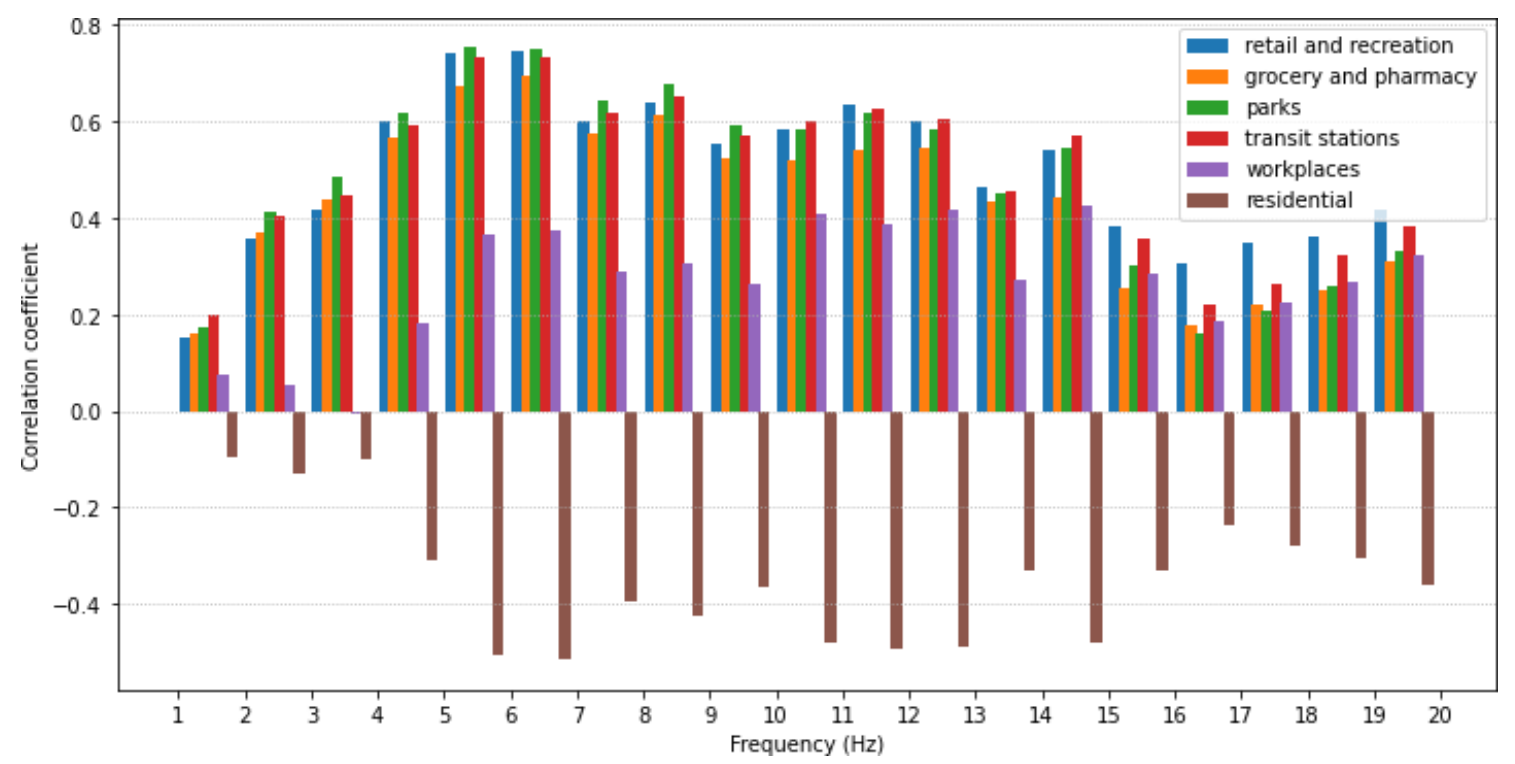

Figure 3. Correlation coefficient between the seismic rms in a narrow $1 \mathrm{~Hz}$ frequency band from 1 to $20 \mathrm{~Hz}$ at station R6BB7 and the Google community mobility in the high categories of retail and recreation, groceries and pharmacies, parks, transit stations, workplaces, and residential premises. The period considered extends from 15 February to 1 October 2020, and the highest correlation and anticorrelation are identified between 4 and $14 \mathrm{~Hz}$.

The index in the residential category is calculated using the average amount of time in hours spent at places of residence by individual users in a given day and geographic area. The workplace index is calculated as a count of users spending more than $1 \mathrm{~h}$ at their places of work each day and is aggregated by their place of residence. The index for all the remaining categories counts the number of unique users who visited a public place in the given category on a given day, with individual users contributing at most once to each category and up to four pairs of category-location per day (Aktay et al., 2020).

These data are imperfect on many levels, especially when applied to a city in Mexico. The raw data only sample the portion of the population with stable access to the internet actively using Google services. Evidence shows that the urban population is far better connected than the rural, and Android is by far the leading operative system, with over $80 \%$ of the Mexican market (Borbón González et al., 2018; MartínezDomínguez and Mora-Rivera, 2020).

The data are anonymized using libraries of differentially private algorithms, which add Laplace noise to protect each metric with differential privacy (Aktay et al., 2020). Furthermore, metrics for which the geographic region is smaller than $3 \mathrm{~km}^{2}$, or for which the differentially private count of contributing users after noise addition is smaller than 100, are discarded. The original data are by design far from transparent, leading to significant uncertainties in features such as the number of people and the delimitation of the locations sampled (e.g., Lecocq et al., 2020).
In this work, we used data for the state of Querétaro, the smallest spatial granularity level available for the region. Since the QMZ contains $\sim 64 \%$ of the population and the largest portion of the urban population likely to use such mobile technology in the state (INEGI, 2016), we consider this approximation acceptable for our purposes.

With those limitations, in the absence of a better option, these community mobility data offer the best solution to specifically track the social response of the population to lockdown measures and compare them to ambient noise monitoring.

\section{Results and discussion}

Significant reductions of the seismic rms following the implementation of lockdown measures are observed at all narrow frequency bands between 1 and $20 \mathrm{~Hz}$. Higher correlation coefficients between community mobility and the seismic rms were obtained between 4 and $14 \mathrm{~Hz}$, leading us to concentrate on that frequency range, which is consistent with Lecocq et al. (2020).

To better interpret the variation of seismic rms relative to community mobility, we converted those values to percentage of change according to the corresponding day of the week during a baseline period. The baseline is calculated as the median value for the corresponding day of the week from 13 January to 2 March, excluding 3 February, which was a holiday. This baseline period is different from the one used for Google community mobility; it is a larger period, starting later to avoid any influence from the end of the Christmas 


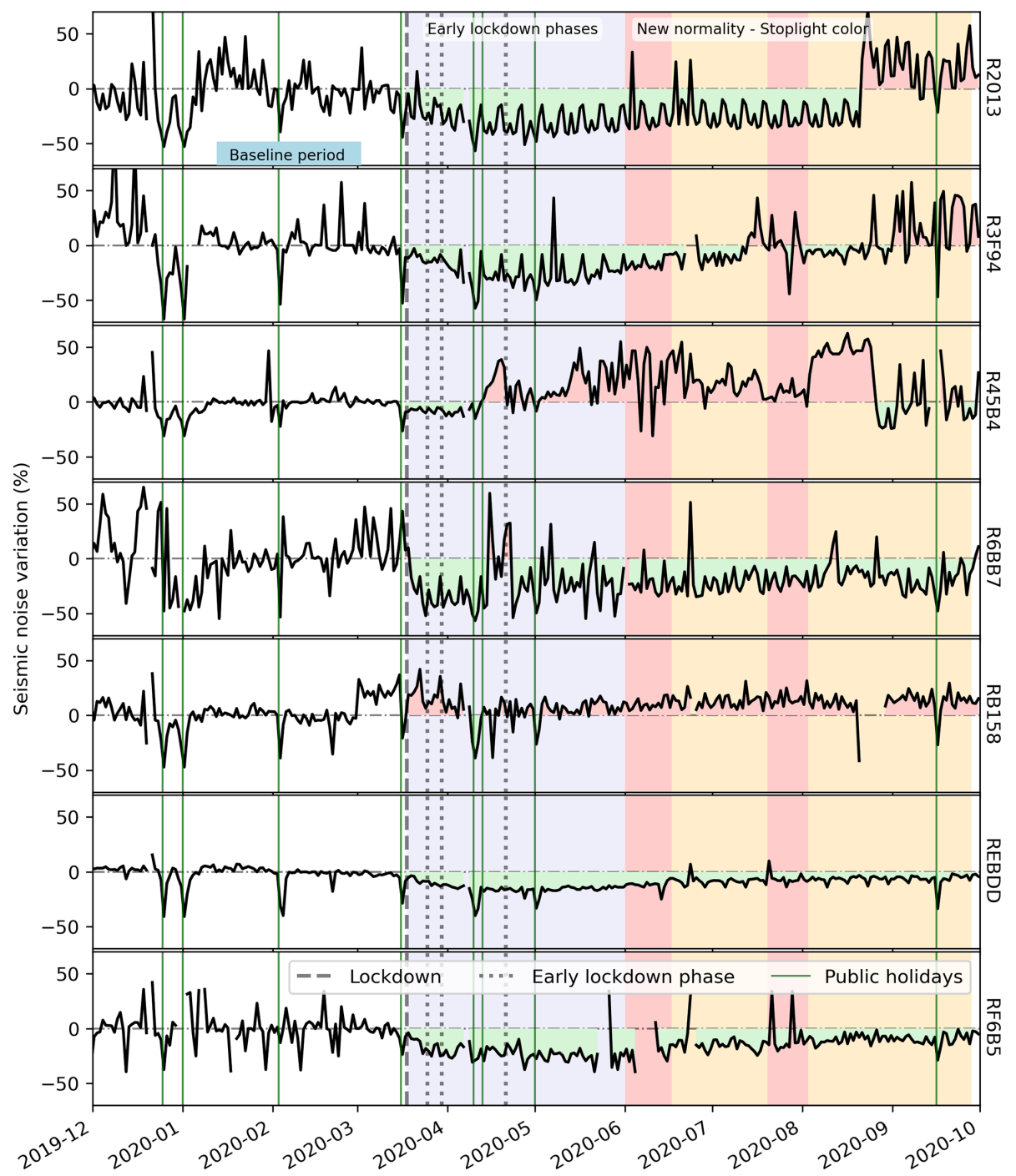

Figure 4. Variation of seismic rms between 4 and $14 \mathrm{~Hz}$ in percent at all seven stations of the network relative to the median of the corresponding day of the week during the baseline period of 13 January to 2 March. The public holidays are indicated with green vertical lines, and the implementation of lockdown measures is indicated as the black dashed line. The purple span corresponds to the early lockdown phases, and the red and orange spans after 1 June are the corresponding stoplight color for the "new normality".

and New Year school holidays. The baseline period finishes before the announcement by the World Health Organization that COVID-19 had officially become a pandemic.

The resulting time series show less impact from weekends, but they are characterized by lower noise levels (Fig. 4). Instead, days such as public holidays with anthropogenic noise levels that are out of the ordinary are specifically emphasized, with reductions from $-20 \%$ to $-50 \%$ registered at all stations. With the implementation of the first lockdown measures, the relative noise level started to progressively decrease at all stations except for RB158, located in the Benito Juárez industrial park, where the noise level remained $20 \%$ to $50 \%$ higher than the baseline from early March. Noise levels at this station decreased after the declaration of a sanitary emergency and on the Good Friday holiday but then displayed a slow progressive increase until 1 June, and then it remained significantly above baseline. This suggests a sustained higher-than-normal level of activity in the close vicinity of the industrial park even as the Mexican government suspended non-essential activities in the public, private, and social sectors. This high level of activity could be the result of essential activity such as the delivery of food and supplies and would explain why this higher level of activity was later sustained.

All the other stations displayed significant noise reduction until at least the end of the Easter holidays (12 April 2020). During this period, station R45B4, located at the Universidad Tecnológica de Querétaro (UTQ) campus, displayed the smallest change, with noise levels dropping by less than $10 \%$, followed by sustained increased levels up to $30 \%$ 


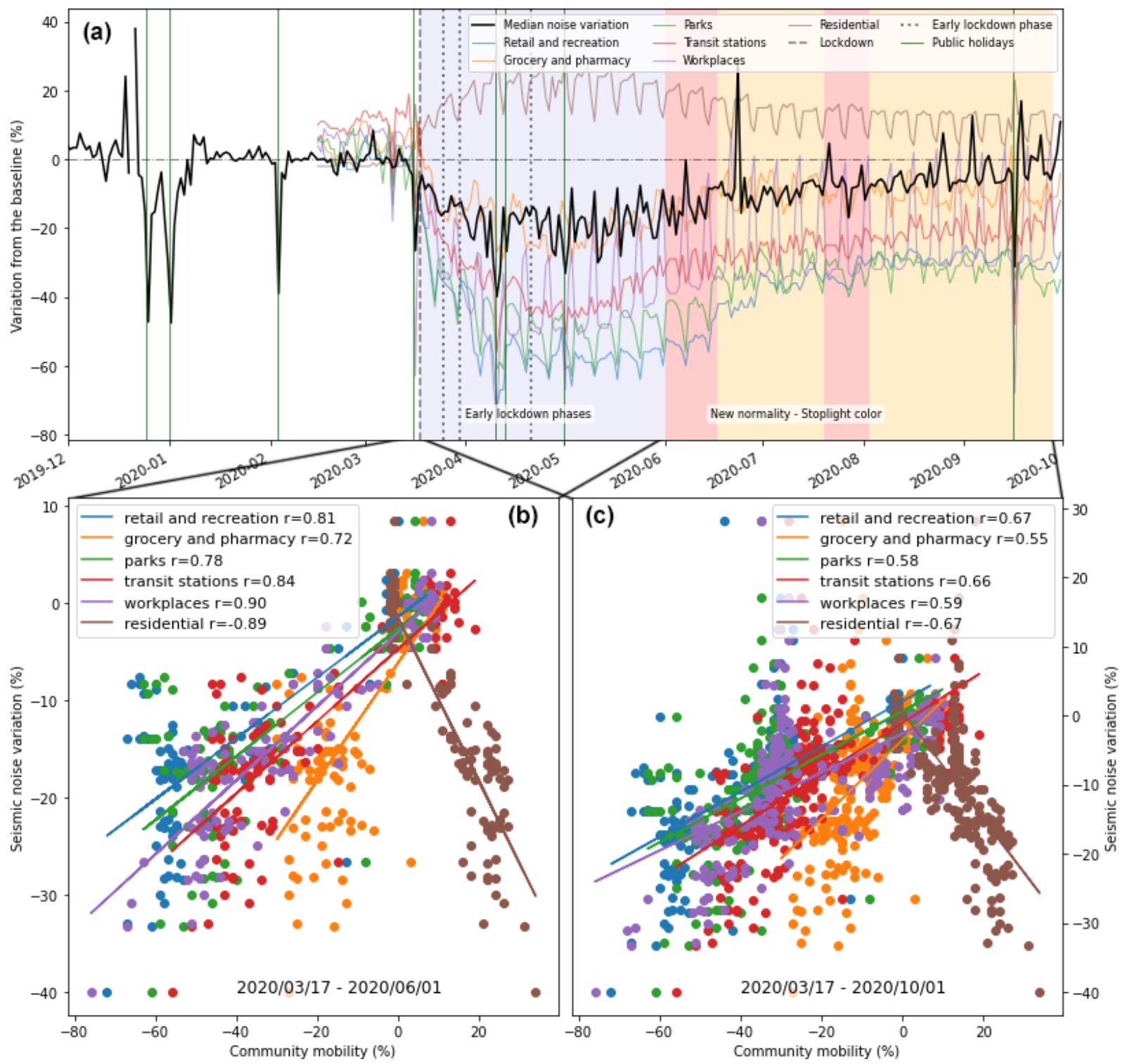

Figure 5. (a) Median of the variation of the seismic rms at all stations relative to the median of the corresponding day of the week during the baseline period of 13 January to 2 March and variation of the Google community mobility in six high-level categories. The public holidays are indicated with blue dashed lines, and the implementation of lockdown measures is indicated as the black dashed line. The purple span corresponds to the early lockdown phases, and the red and orange spans after 1 June are the corresponding stoplight color for the "new normality". Cross-plot between the median seismic rms of the network and the Google community mobility in six high-level categories during the early lockdown phases (b) and including the new normality (c). The Spearman correlation coefficients between the median seismic rms and each category of community mobility are provided in the legend.

above the baseline as a result of roadwork on a neighboring avenue. This high level of seismic rms at this station holds until the end of August. It can safely be attributed to the roadwork in the near-field rather than a specifically lockdownrelated human activity change.

The median of all the stations better illustrates this change, with a progressive decrease through lockdown phases 1 and 2 and the state of sanitary emergency until the Good Friday holiday (10 April 2020) that reached $\sim 40 \%$ under the baseline (Fig. 5a). The median then slightly increased, followed by a decrease after phase 3 of the lockdown until 1 May (Labor Day holiday). The noise then progressively increased again until the implementation of the stoplight system of the NN on 1 June. From the end of the Easter holidays to 1 June, stations REBDD, RF6B5, R3F94, R2013, and R6BB7 maintained an average noise level of $-19.31 \%$, $-27.93 \%,-31.99 \%,-32.70 \%$, and $-35.68 \%$, respectively (Fig. 4). 

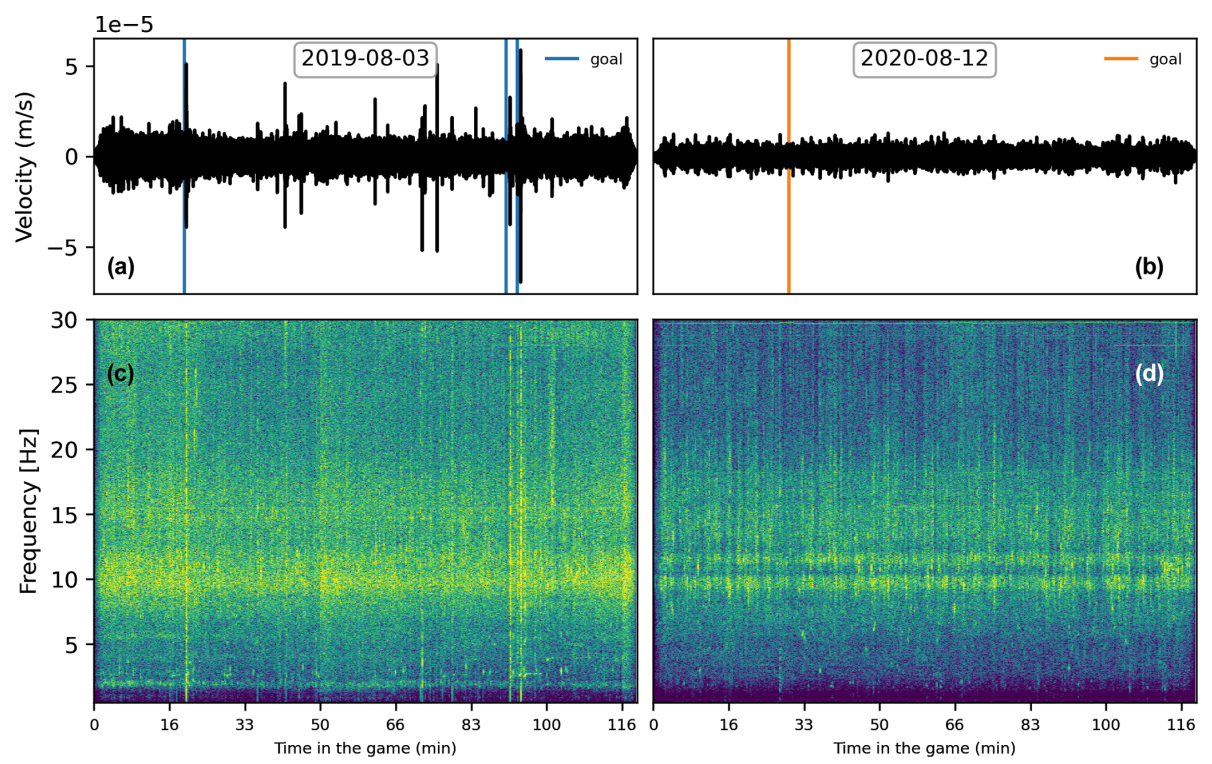

$-150 \quad$ Amplitude $\left(\mathrm{m}^{2} / \mathrm{s}^{4} / \mathrm{Hz}[\mathrm{dB}]\right) \quad-115$

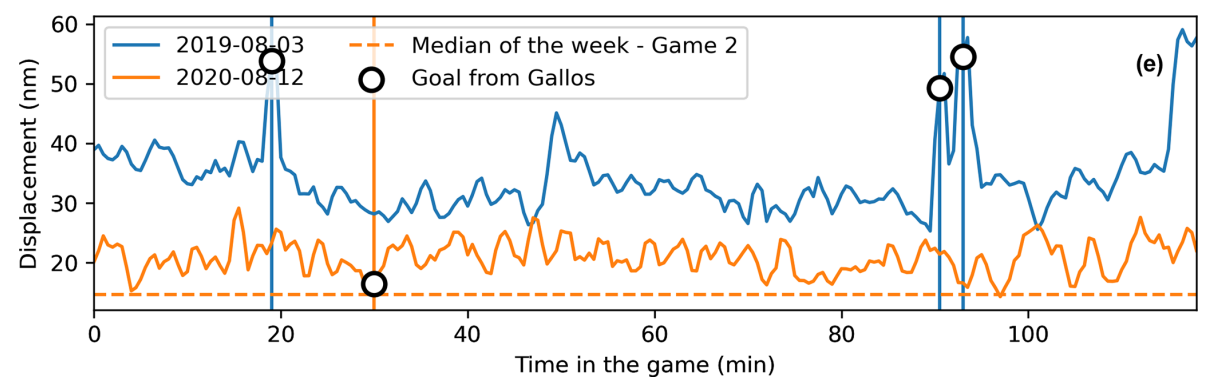

Figure 6. Seismic signal recorded by station REBDD during the football games between the Gallos Blancos of Querétaro and the Cruz Azul of Mexico City in the Corregidora soccer arena on 3 August 2019 and 12 August 2020, respectively. Panels (a) and (b) are the waveforms, and panels (c) and (d) are the spectrograms for each respective game. Panel (e) compares the seismic rms between the two games in the 4-14 Hz frequency range.

During the NN, the stoplight changed from red to orange, with a subsequent relaxation of restrictions accompanied by a consistent progressive increase in the level of noise. As the infection risk increased, the stoplight was turned red again on 20 July for 2 weeks, during which the seismic rms slightly decreased again. The stoplight was then turned orange again until 1 October, when it changed to yellow, and the seismic rms increased back to baseline levels.

From mid-August, station R2013 at the UNAM campus displayed a significant increase in the seismic rms, which was on average $30 \%$ above the baseline. This sharp increase when some restrictions were still in place resulted from the relocation of the instrument from an office to a noisier site.

\subsection{Sporting events}

The station REBDD located in the Corregidora soccer arena also offers an interesting perspective on the contribution of public attendance to the recorded seismic noise. Seismometers in soccer stadiums are regularly used in Mexico as an entertaining tool to teach basic scientific research methodologies and seismology to undergraduate students (e.g., Melgar and Pérez-Campos, 2011), which echoes similar initiatives at sporting events worldwide (e.g., Vidale, 2011; Díaz et al., 2017). In Querétaro, all games had been canceled with the implementation of the early lockdown measures until midJuly, when authorities allowed games without public attendance. This situation makes for a good opportunity to compare observations during games played before and after the beginning of the confinement. In what follows, we look at data from two games played by the first-division Gallos Blancos of Querétaro soccer club against the Cruz Azul soccer club of Mexico City (3 August 2019 and 12 August 2020, Fig. 6) as well as one against the Águilas del América soccer club of Mexico City (9 February and 16 August 2020, Fig. 7). The seismic rms is calculated with the method described above but with a window reduced to $100 \mathrm{~s}$.

Both games played against the Cruz Azul team were won by Gallos Blancos with scores of 3-0 and 1-0, respectively. During the first game, which occurred with an audience of 

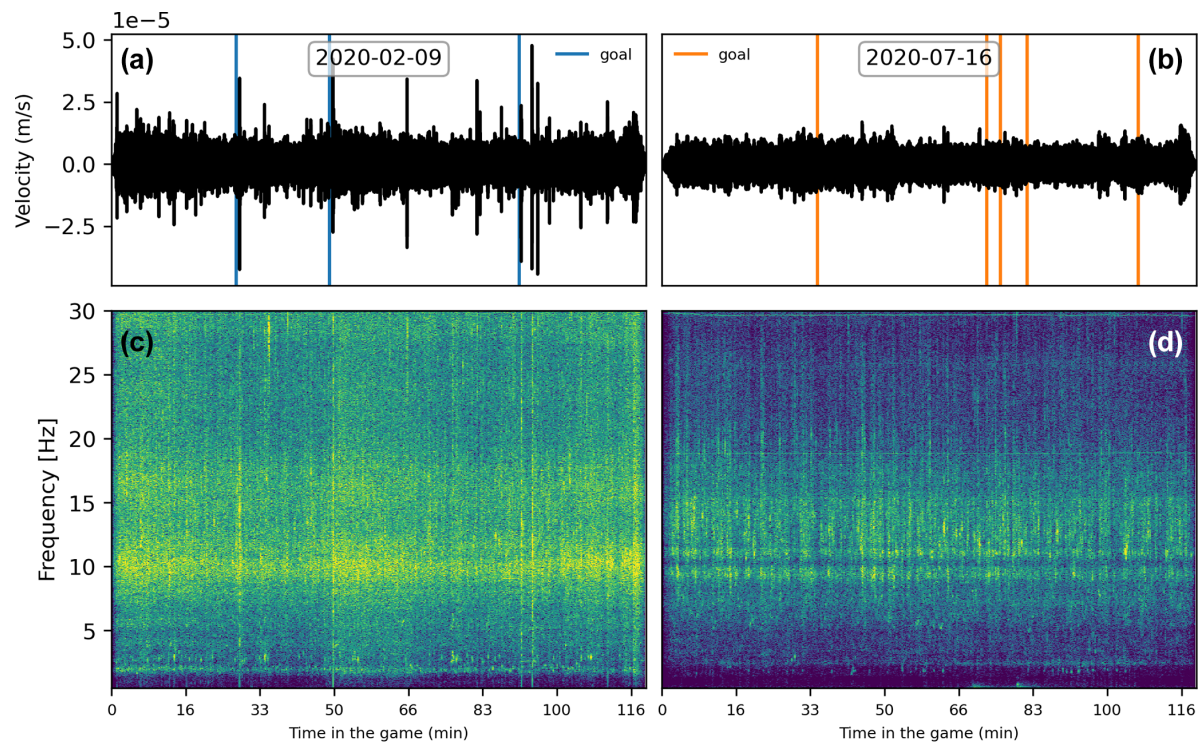

(d)
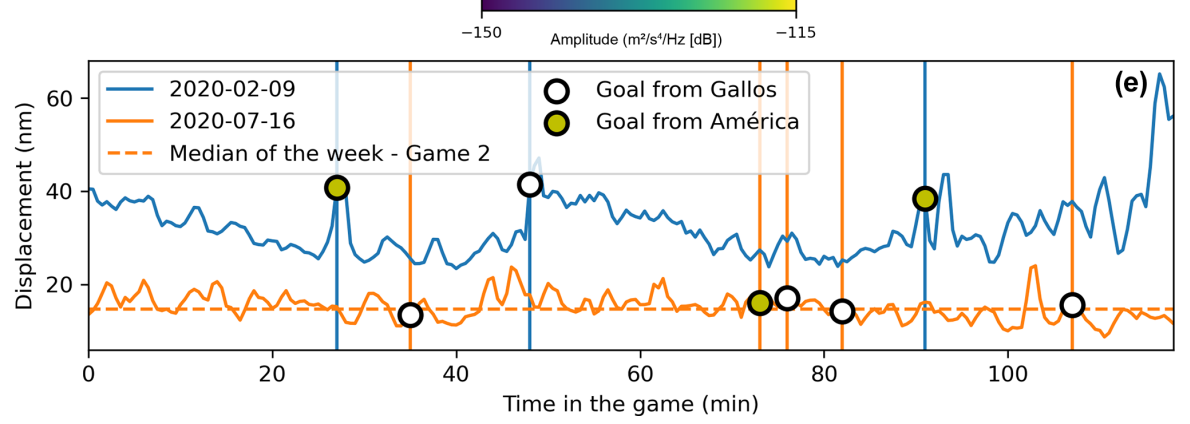

Figure 7. Seismic signal recorded by station REBDD during the football games between the Gallos Blancos of Querétaro and the Club América of Mexico City in the Corregidora soccer arena on 9 February and 16 July 2020, respectively. Panels (a) and (b) are the waveforms, and panels (c) and (d) the spectrograms for each respective game. Panel (e) compares the seismic rms between the two games in the 4-14 Hz frequency range.

29339 supporters, a clear signature can be identified at the moments Gallos Blancos scored goals, with a significant increase (Fig. 6) in noise. The half-time and especially the end of the game are also characterized by a relatively higher noise level than the rest of the game, which could potentially be attributed to the enthusiasm of the supporters at the final score. This development contrasts with the 16 August 2020 game played without an audience. The entire game remained at a relatively low level of noise very close to the median of the week for that time of the day (Fig. 6). The only goal, at the 29th minute of the game, does not emerge from the background noise as only the players were present to celebrate it.

A similar pattern is observed during the matches against the Águilas del América team. The first game on 9 February 2020, with 34050 supporters, was won 1-2 by América with noise levels consistently higher than the baseline for that time of the day on a Sunday and with clear spikes every time a goal was scored by either team. This pattern again shows the impact of the supporters on the recorded seismic noise, which is further emphasized in contrast to the 16 July 2020 game during which goals scored do not significantly emerge from the background signal.

\subsection{Correlation with mobility}

The different categories of community mobility were compared to the variations of noise levels to identify the one most affected by lockdown measures. The different correlation coefficient obtained for each category of community mobility sheds light on the impact of lockdown measures (Fig. 5). The metrics of community mobility are based on data from Google users in the state of Querétaro who use location history, the majority of which are assumed to live in the QMZ. The median of network stations rather than individual stations was therefore compared to the community mobility to better correspond to the sampled population.

The median seismic rms has a high correlation with all the categories except the residential one, but the retail and recreation (0.67), transit station (0.66), and workplace (0.59) categories are the highest. With non-essential workers invited to 
shelter at home, this is an expected outcome reinforced by the strongly anticorrelated $(-0.67)$ residential category (Fig. 5c). All correlation coefficients are highly significant with $p$ values smaller than $\times 10^{-15}$. The relationship between seismic rms and the different categories of community mobility is noticeably higher during the early phases of lockdown (Fig. 5b). This could reflect the more complex mobility pattern people adopted during the new normality, as the authorities progressively encouraged the reopening of the economy with the help of sanitary measures.

Anthropogenic seismic noise recorded in cities is typically generated by various processes such as cultural and sporting events, individual and public commuter traffic, and the production and transportation of different kinds of goods (e.g., Groos and Ritter, 2009). Traffic in particular heavily influences the frequency range from $\sim 1 \mathrm{~Hz}$ to more than $45 \mathrm{~Hz}$, with variation with respect to urban location due to the influence of subsurface conditions. As a result, geophysical sensing such as fiber-optic distributed acoustic sensing (DAS) has recently proven to be capable of providing remarkably resolved statistics about public infrastructure utilization across many large sectors of a city (Lindsey et al., 2020). Surface waves generated by vehicles in stratified soil have been shown to be mainly restricted to the $2-20 \mathrm{~Hz}$ frequency band. Vehicle-induced ground vibrations are generated by the pitch and axle hop modes of the vehicle coupling to the road. Although far-field vibration levels depend on vehicle speed, road unevenness, the vehicle itself, and soil characteristics, vibration frequencies attributed to axle hop modes depend on vehicle distance and velocity (Lombaert et al., 2000; Lombaert and Degrande, 2001).

The seismic noise recorded by stations, which are all within $5 \mathrm{~km}$ of the main roads in the state in a busy urban environment, is relatively similar across all stations in our frequency band of interest and has a specific temporal pattern that suggests a ubiquitous source. This has been characterized as traffic-dominated anthropogenic noise (e.g., Boese et al., 2015; Green et al., 2017) and indicates that the method likely provides a good proxy for the temporal variation of traffic volume. With a lot of people working from home or losing their jobs during the lockdown, our results could in large part indirectly show the decrease in commuter traffic.

\section{Conclusions}

Like in a lot of populated places around the world, the effect of lockdown measures was observed as a decrease in highfrequency seismic noise in the city of Querétaro. Our results specifically show the benefit of using a network of low-cost Raspberry Shake stations to investigate the temporal and spatial variation of anthropogenic noise at a city scale.

While the tracked variation of human-generated noise has high similarity to community mobility as obtained from mobile technology, it yields a finer resolution that could ef- fectively single out localized zones of increased noise level caused by more activity, such as in the Benito Juárez industrial park, or construction work, such as at the campus of the Universidad Tecnológica de Querétaro.

The privacy concerns associated with mobile-technologybased community mobility data require a low resolution to anonymize original user data. Along with a higher resolution, anthropogenic seismic noise has the advantage of being anonymized by definition and does not require the population to share their personal data.

While we observed the contribution to anthropogenic noise in the near-field of sources such as construction work and sporting events, the observed correlation between seismic noise and mobility at the city scale is consistent with the traffic-dominated nature of anthropogenic seismic noise in urban areas. Although observing variations of traffic volumes in the seismic signal is not monitoring the lockdown per se, it proves to be a reliable proxy for human activity, especially at the city scale with such a network.

Data availability. Data for stations R3F94, RB158, and R3F94 are openly accessible as part of the citizen scientist earthquake monitoring network (AM) through FDSN Web Services (https://doi.org/10.7914/SN/AM; Raspberry Shake Community et al., 2016). The remaining data used in this study are available upon request to the corresponding author.

Author contributions. RSMDP, VHMR, and XPC designed the study. All the authors analyzed the seismic data. RSMDP, VHMR, and XPC wrote the paper. All the authors interpreted the results and revised the article.

Competing interests. The authors declare that they have no conflict of interest.

Special issue statement. This article is part of the special issue "Social seismology - the effect of COVID-19 lockdown measures on seismology". It is not associated with a conference.

Acknowledgements. This work is supported by grant CONACYT299766 and CONCYTEQ. Raphael S. M. De Plaen acknowledges support from a UNAM-DGAPA postdoctoral scholarship. We also thank the following institutions: CCU-UNAM, UTEQ, UPQ, CECEQ, Estadio Corregidora, and Parque Industrial Benito Juárez for allowing us to install equipment in their facilities.

Review statement. This paper was edited by Paula Koelemeijer and reviewed by two anonymous referees. 


\section{References}

Aktay, A., Bavadekar, S., Cossoul, G., Davis, J., Desfontaines, D., Fabrikant, A., Gabrilovich, E., Gadepalli, K., Gipson, B., Guevara, M., Kamath, C., Kansal, M., Lange, A., Mandayam, C., Oplinger, A., Pluntke, C., Roessler, T., Schlosberg, A., Shekel, T., Vispute, S., Vu, M., Wellenius, G., Williams, B., and Wilson, R. J.: Google COVID-19 Community Mobility Reports: Anonymization Process Description (version 1.0), ArXiv [preprint], arXiv:2004.04145, 8 April 2020.

Anthony, R. E., Ringler, A. T., Wilson, D. C., and Wolin, E.: Do low-cost seismographs perform well enough for your network? An overview of laboratory tests and field observations of the OSOP raspberry shake 4D, Seismol. Res. Lett., 90, 219-228, https://doi.org/10.1785/0220180251, 2019.

Boese, C. M., Wotherspoon, L., Alvarez, M., and Malin, P.: Analysis of anthropogenic and natural noise from multilevel borehole seismometers in an urban environment, Auckland, New Zealand, Bull. Seismol. Soc. Am., 105, 285-299, https://doi.org/10.1785/0120130288, 2015.

Borbón González, A. D., Cristina, T. B., and Romero Dessens, L. F.: Caracterización del mercado mexicano de teléfonos celulares inteligentes o smartphones, INVURNUS, 13, 21-31, 2018.

Cannata, A., Cannavò, F., Di Grazia, G., Aliotta, M., Cassisi, C., De Plaen, R. S. M., Gresta, S., Lecocq, T., Montalto, P., and Sciotto, M.: Seismic evidence of the COVID-19 lockdown measures: a case study from eastern Sicily (Italy), Solid Earth, 12, 299-317, https://doi.org/10.5194/se-12-299-2021, 2021.

Dias, F. L., Assumpção, M., Peixoto, P. S., Bianchi, M. B., Collaço, B., and Calhau, J.: Using Seismic Noise Levels to Monitor Social Isolation: An Example From Rio de Janeiro, Brazil, Geophys. Res. Lett., 47, e2020GL088748, https://doi.org/10.1029/2020GL088748, 2020.

Díaz, J., Ruiz, M., Sánchez-Pastor, P. S., and Romero, P.: Urban Seismology: On the origin of earth vibrations within a city, Sci. Rep., 7, 1-11, https://doi.org/10.1038/s41598-017-15499-y, 2017.

Diaz, J., Schimmel, M., Ruiz, M., and Carbonell, R.: Seismometers Within Cities: A Tool to Connect Earth Sciences and Society, Front. Earth Sci., 8, 1-7, https://doi.org/10.3389/feart.2020.00009, 2020.

Economic and Development Review Committee: OECD Economic Surveys: Mexico 2019, OECD, https://doi.org/10.1787/19990723, 2019.

Google: COVID-19 Community Mobility Report, COVID-19 Community Mobility Report, available at: https://www.google.com/ covid19/mobility?hl=en, last access: 24 September 2020.

Green, D. N. and Bowers, D.: Seismic Raves: Tremor Observations from an Electronic Dance Music Festival, Seismol. Res. Lett., 79, 546-553, https://doi.org/10.1785/gssrl.79.4.546, 2008.

Green, D. N., Bastow, I. D., Dashwood, B., and Nippress, S. E. J.: Characterizing broadband seismic noise in Central London, Seismol. Res. Lett., 88, 113-124, https://doi.org/10.1785/0220160128, 2017.

Groos, J. C. and Ritter, J. R. R.: Time domain classification and quantification of seismic noise in an urban environment, Geophys. J. Int., 179, 1213-1231, https://doi.org/10.1111/j.1365246X.2009.04343.x, 2009.

INEGI: Panorama sociodemográfico de Queretaro 2015, Encuesta Intercensal 2015, Instituto Nacional de Estadística y Geografía, México, available at: https://www.inegi.org.mx/ programas/intercensal/2015/ (last access: 12 March 2021), 2016. Lecocq, T., Hicks, S. P., Van Noten, K., van Wijk, K., Koelemeijer, P., De Plaen, R. S. M., Massin, F., Hillers, G., Anthony, R. E., Apoloner, M.-T., Arroyo-Solórzano, M., Assink, J. D., Büyükakpınar, P., Cannata, A., Cannavo, F., Carrasco, S., Caudron, C., Chaves, E. J., Cornwell, D. G., Craig, D., den Ouden, O. F. C., Diaz, J., Donner, S., Evangelidis, C. P., Evers, L., Fauville, B., Fernandez, G. A., Giannopoulos, D., Gibbons, S. J., Girona, T., Grecu, B., Grunberg, M., Hetényi, G., Horleston, A., Inza, A., Irving, J. C. E., Jamalreyhani, M., Kafka, A., Koymans, M. R., Labedz, C. R., Larose, E., Lindsey, N. J., McKinnon, M., Megies, T., Miller, M. S., Minarik, W., Moresi, L., MárquezRamírez, V. H., Möllhoff, M., Nesbitt, I. M., Niyogi, S., Ojeda, J., Oth, A., Proud, S., Pulli, J., Retailleau, L., Rintamäki, A. E., Satriano, C., Savage, M. K., Shani-Kadmiel, S., Sleeman, R., Sokos, E., Stammler, K., Stott, A. E., Subedi, S., Sørensen, M. B., Taira, T., Tapia, M., Turhan, F., van der Pluijm, B., Vanstone, M., Vergne, J., Vuorinen, T. A. T., Warren, T., Wassermann, J., and Xiao, H.: Global quieting of high-frequency seismic noise due to COVID-19 pandemic lockdown measures, Science, 369, 1338-1343, https://doi.org/10.1126/science.abd2438, 2020.

Lindsey, N. J., Yuan, S., Lellouch, A., Gualtieri, L., Lecocq, T., and Biondi, B.: City-Scale Dark Fiber DAS Measurements of Infrastructure Use During the COVID-19 Pandemic, Geophys. Res. Lett., 47, e2020GL089931, https://doi.org/10.1029/2020GL089931, 2020.

Lombaert, G. and Degrande, G.: Experimental validation of a numerical prediction model for free field traffic induced vibrations by in situ experiments, Soil Dyn. Earthq. Eng., 21, 485-497, https://doi.org/10.1016/S0267-7261(01)00017-3, 2001.

Lombaert, G., Degrande, G., and Clouteau, D.: Numerical modelling of free field traffic-induced vibrations, Soil Dyn. Earthq. Eng., 19, 473-488, https://doi.org/10.1016/S02677261(00)00024-5, 2000.

Martínez-Domínguez, M. and Mora-Rivera, J.: Internet adoption and usage patterns in rural Mexico, Technol. Soc., 60, 101226, https://doi.org/10.1016/j.techsoc.2019.101226, 2020.

Melgar, D. and Pérez-Campos, X.: How a Soccer Stadium Helps with an Education in Science and Seismology, Seismol. Res. Lett., 82, 115-119, https://doi.org/10.1785/gssrl.82.1.115, 2011.

OECD/ILO: Tackling Vulnerability in the Informal Economy, OECD Publishing, Paris, https://doi.org/10.1787/939b7bcd-en, 2019.

Poli, P., Boaga, J., Molinari, I., Cascone, V., and Boschi, L.: The 2020 coronavirus lockdown and seismic monitoring of anthropic activities in Northern Italy, Sci. Rep., 10, 9404, https://doi.org/10.1038/s41598-020-66368-0, 2020.

Raspberry Shake Community, OSOP, S.A., and Gempa GmbH: AM Raspberry Shake, FDSN, https://doi.org/10.7914/SN/AM, 2016.

Riahi, N. and Gerstoft, P.: The seismic traffic footprint: Tracking trains, aircraft, and cars seismically, Geophys. Res. Lett., 42, 2674-2681, https://doi.org/10.1002/2015GL063558, 2015.

Secretaría de Salud: Consejo de Salubridad General declara emergencia sanitaria nacional a epidemia por coronavirus COVID-19, available at: http://www.gob.mx/salud/prensa/consejo-desalubridad-general-declara-emergencia-sanitaria-nacional-aepidemia-por-coronavirus-covid-19-239301, last access: 30 October 2020a. 
Secretaría de Salud: Secretarías de Salud y de Turismo presentan Lineamiento Nacional para la Reapertura del Sector Turístico, available at: http://www.gob.mx/salud/prensa/secretarias-desalud-y-de-turismo-presentan-lineamiento-nacional-para-lareapertura-del-sector-turistico-243436, last access: 30 October $2020 \mathrm{~b}$.

Vidale, J. E.: Seattle "12th Man Earthquake” Goes Viral, Seismol. Res. Lett., 82, 449-450, https://doi.org/10.1785/gssrl.82.3.449, 2011.

Welch, P.: The use of fast Fourier transform for the estimation of power spectra: A method based on time averaging over short, modified periodograms, IEEE T. Audio Electroacoustic., 15, 7073, https://doi.org/10.1109/TAU.1967.1161901, 1967.
World Health Organisation: Coronavirus Disease (COVID-19) Situation Reports, available at: https://www.who.int/emergencies/ diseases/novel-coronavirus-2019/situation-reports, last access: 19 October 2020.

Xiao, H., Eilon, Z. C., Ji, C., and Tanimoto, T.: COVID19 Societal Response Captured by Seismic Noise in China and Italy, Seismol. Res. Lett., 91, 2757-2768, https://doi.org/10.1785/0220200147, 2020. 